\title{
Three Formative Questions in the Quantitative Literacy Movement
}

Dorothy Wallace

Dartmouth College, dorothy.wallace@dartmouth.edu

Follow this and additional works at: https://digitalcommons.usf.edu/numeracy

Part of the Higher Education Commons, Mathematics Commons, and the Teacher Education and Professional Development Commons

\section{Recommended Citation}

Wallace, Dorothy. "Three Formative Questions in the Quantitative Literacy Movement." Numeracy 12, Iss. 1 (2019): Article 13. DOI: https://doi.org/10.5038/1936-4660.12.1.13 


\title{
Three Formative Questions in the Quantitative Literacy Movement
}

\begin{abstract}
In this essay we remember early discussions attempting to answer three questions that played a formative role in our understanding of and approach to numeracy, quantitative literacy, and quantitative reasoning: (1) What is numeracy? (2) Should the QL movement promote any specific kind of pedagogy? (3) What organizational structure will best support QL?

As the QL movement has progressed, these three questions continue to be difficult to answer. As a result, they have been useful formative guides for institutions and organizations seeking to improve the quantitative reasoning of students. Now that the quantitative literacy movement has a firmer standing in the college curriculum, we offer for consideration some next steps, based on these three questions, for the QL movement in general and the National Numeracy Network in particular.
\end{abstract}

\section{Keywords}

Numeracy, quantitative literacy, quantitative reasoning, National Numeracy Network

\section{Creative Commons License}

\section{cc) (i) (8)}

This work is licensed under a Creative Commons Attribution-Noncommercial 4.0 License

\section{Cover Page Footnote}

Dorothy Wallace, math professor at Dartmouth University, was Co-PI of one of the first Math across the Curriculum projects (1995-2000), the 2000 New Hampshire CASE Professor of the Year, and member of the Quantitative Literacy Design Team listed in Mathematics and Democracy (2001). She has broad background in many kinds of mathematics, with approximately 100 publications in pure, applied, and educational topics. In the last 9 years, she has supervised 45 undergraduates conducting research through internships, independent study, and senior theses. Her research papers in mathematical biology include 29 undergraduates among her coauthors. She was a charter board member of the National Numeracy Network, a founding co-editor of this journal, and is now Contributing Editor. 


\section{Introduction}

My contribution to Numeracy's "Roots and Seeds" collection should probably begin with the disclaimer that, in writing about the beginnings of the quantitative reasoning movement, I necessarily position myself as someone whose original interests lay elsewhere. In 1994, I had the crazy idea of developing a math and art course in which students would learn the rudiments of abstract algebra through the symmetry groups of the plane, and I thought that the National Science Foundation might support the project. One thing led to another, and Dartmouth got one of the few Mathematics and its Applications Throughout the Curriculum grants, leading to the involvement of around 40 faculty members and development of a suite of courses and course materials. ${ }^{1}$ In addition to creating materials and courses, we hosted workshops for faculty development and helped get projects started at other institutions. I, for one, thought the ticket to better math education might lie in math's interdisciplinary connection to many other subjects. I thought (and still think) that interdisciplinary connection is important, but the forces acting on math education were moving in a slightly different way, toward the idea of quantitative literacy. Ultimately quantitative literacy proved to be a term that institutions could get behind, because members of these institutions all want their graduates to be literate, whatever that means.

I distinctly remember the very first general meeting of all participants in our NSF-funded Math Across the Curriculum (MATC) project. It was nearly derailed completely when one person suggested that before we create any course materials or design any courses, we should all agree on which word processing program we would use. As the principal investigator running the meeting, and many years junior to most of those in the room, I immediately imagined a fracas breaking out between the users of Word (nearly all non-mathematicians) and the users of Tex (nearly all mathematicians). Any fool could see that such a quarrel would be a bad start to interdisciplinary collaboration. The impending crisis was averted when the steering committee members quickly took it upon themselves to consider the suggestion at a later time. In the end, the question of Word versus Tex was an unimportant one. But it's an interesting example of the kind of question that can spark endless debate, that eventually needs to be answered one way or another, and that might be better off left unanswered for some period of time.

Toward the end of the Mathematics Across the Curriculum project at Dartmouth, I became involved with the Quantitative Literacy Design Team - a

\footnotetext{
${ }^{1}$ https://nsf.gov/awardsearch/showAward?AWD ID=9455965\&HistoricalAwards=false (accessed 11/10/2018)
} 
group of individuals, led by Robert Orrill, ${ }^{2}$ which were brought together several times over a period of years to consider strategies that might improve the quantitative literacy of students at the high school and college levels. It was the Design Team discussions that ultimately led to the creation of the National Numeracy Network (NNN), and when I think about those early discussions, I am intrigued by questions about quantitative literacy that were raised then and continue to be brought up repeatedly today. Because these questions are difficult to answer, the debate around them has been a formative force in the QL movement. This essay recalls some of the questions and revisits some of the answers that were suggested by the Quantitative Literacy Design Team. Perhaps this recollection and re-visitation will provide some useful ideas for the way forward.

\section{Three Questions}

\section{What Is Numeracy?}

The question "What is numeracy?" was at the heart of Quantitative Literacy Design Team discussions that led to the first essay in Mathematics and Democracy (Steen 2001) and that initiated the NNN. I hope that colleagues who were present at the time will forgive my imperfect memory as I try to describe the tenor of the numerous, lengthy discussions around this question.

Discussions often centered around our conviction that there was both a societal and an educational need to improve the quantitative skills of our students. We were sure that our students' habit of avoiding data, calculation, or any reasoning that required a quantitative approach was something to be discouraged. We agreed that the educational system was falling short on improving the quantitative literacy of students, and we were not afraid to be judgmental about it. And though we agreed on so much, we were incapable of framing a tight definition of this very important thing-numeracy / quantitative literacy / quantitative reasoning - that we wanted to promote. The longer we talked, the more items we added to the universe we were trying to describe. We were sure of one thing though: we knew it when we saw it.

It is therefore not surprising that in the opening essay in Mathematics and Democracy, we listed ten elements of quantitative literacy, ranging from emotive (confidence) to practical (decision making) to abstract (algebraic manipulation), with an accompanying nod to the liberal arts (cultural appreciation). Our list was ambitious, addressing cognitive, social, and educational aspects of numeracy with no attempt to prioritize any of them. Taken as a whole, it was not really actionable

\footnotetext{
${ }^{2}$ Executive Director, National Council of Education and the Disciplines, Princeton; before that,
} Executive Director, Office of Academy Affairs, College Board, New York City, 1985-1999. 
by an individual instructor, nor would success in all these aspects be measurable by a single test. Generous funding from the Pew Foundation allowed us to meet for many days over the course of several years, but no amount of funding could have kept us in a room long enough to agree on a short definition of quantitative literacy. Even now, the NNN website offers three competing definitions, each with a conveniently different title-numeracy, quantitative literacy, and quantitative reasoning - and points the reader to four collections of articles that try to define the concept. ${ }^{3}$ One of these collections is, of course, Mathematics and Democracy, which offers not one, but many possible definitions.

Practically speaking, the reason to have a fairly tight definition of numeracy is so that an instructor or institution can set a goal for what a quantitatively literate person should be able to do. With this, it is possible to design a tool to measure whether the goal has been reached, either on the individual or population level. Assessment, usually on the individual level, has been an ongoing theme of Numeracy (Vacher 2015). It has become more important as colleges and universities set institutional requirements or, even more critically, entrance requirements (Frith and Prince 2018). With such requirements come the need for assessment tools. These tools lead, necessarily, to a working definition of quantitative literacy that is far narrower than most descriptions would suggest. Constrained thus, the push for numeracy loses considerable breadth and power. A recent article by Craig and Guzman (Craig 2018) suggests that it is time to reopen the thorny question of defining what we are about here by imposing a theoretical framework upon the whole quantitative literacy endeavor. The authors rework a social theory of literacy so that it applies for numeracy. Theoretical frameworks are useful guides for science and education, but it is interesting to note that no clean definition of quantitative literacy, numeracy, or quantitative reasoning emerges in that article.

My best response to the quandary over how to define numeracy/quantitative literacy is to point out that, on an institutional level, we educate populations, not individuals (Wallace 2009, 2013). A limited definition of numeracy enables assessment of the success of a single course or course requirement, but it fails to capture the goals of higher education as a whole, which should include the creation of "a population of extreme variability in expertise, a diffusion of specialized knowledge across disciplinary boundaries, and production of strong K-12 teachers" (Wallace 2013). The question of how quantitative literacy education should be measured with respect to an entire subpopulation (such as the class of 2018 at your institution) has not been thought through, but doing so could give us the connection we need between the general themes laid out in

\footnotetext{
${ }^{3}$ http://www.nnn-us.org/What-is-Numeracy (accessed 11/10/2018)
} 
Mathematics and Democracy and the concrete assessment tools developed for specific institutional purposes.

\section{Should the QL Movement Promote Any Specific Kind of Pedagogy?}

The question of whether the QL movement should promote any specific kind of pedagogy came up early in the discussions leading to formation of the NNN and the publication of Mathematics and Democracy. There was general recognition that it is possible to teach mathematics (or anything, for that matter) badly. Because of the extent to which future quantitative reasoning courses, texts, or requirements would extend the reach of mathematics, the Design Team was justifiably concerned that unproductive approaches to teaching traditional math topics would be implemented in QR courses to an equally unproductive end. Along with the idea of quantitative literacy as an educational goal, perhaps it would make sense to promote pedagogy likely to help individuals and institutions reach that goal.

Educational research is a tricky business. Results that look convincing may fail to hold in different contexts, with different kinds of students, or at a different level. It is hard to arrange a control group. Research in the field is notoriously difficult to duplicate. And yet, some approaches to teaching and learning do consistently improve student performance (Freeman et al. 2014). Those who promote innovations in teaching wonder why, in the face of strong evidence, faculty fail to adopt these innovations (Henderson and Dancy 2011, Goffe and Kauper 2014, Waldrop 2015). Others, mindful of some of the more spectacular failures in the last century, are not so surprised (Bossé 1995, Klein 2003, Vigdor 2012).

The QL Design Team struggled with positioning of the whole QL enterprise in terms of pedagogy. I'm fairly sure many of my colleagues saw QL as content: a set of skills that everyone should have, like the ability to change a tire (which may be an outdated example). I'm also fairly sure I was not the only one who thought of quantitative reasoning, with its potential emphasis on real world decisions, as a valuable pedagogical tool in the service of improving everybody's grasp of mathematics. Klein, describing math education from 1920 to 1980, writes, "Broadly speaking, the education wars of the past century are best understood as a protracted struggle between content and pedagogy" (Klein 2003). Depending on how we framed our work, we could have positioned quantitative literacy on either side of this struggle or argued that it served both sides equally. If we had decided to make improved pedagogy a major effort of the movement, we would have had to further consider what sorts of teaching to promote. I'm sure that many of us had strong opinions about how to teach, including me of course (Wallace 2017). Such consideration would have taken quite a while. 
Fortunately, that discussion did not happen. Perhaps, on some level, it was due to cowardice. But in looking at the general tenor of arguments about math education, one cannot help but notice that there is no content goal that is derided as "just another fad." Content goals have a stickiness that pedagogical innovations struggle to achieve. By positioning quantitative literacy as representing some collection of basic useful facts, skills, and awareness, we seem to have avoided most of the usual debates around actual teaching. Quantitative reasoning courses and centers are now a feature of a sizeable fraction of undergraduate institutions (Wallace 2018).

Of course, in general, nobody knows if these courses are taught well, whether they encourage further involvement in STEM disciplines, or whether graduates regularly use the skills they learned in their later lives. We don't know if the instructors tend to be innovators in the classroom or if they use a more traditional approach. This absence of information suggests studies that could be done and research articles that could contribute to a better understanding of what works in the QL classroom. Numeracy, of course, would welcome them.

\section{What Organizational Structure Will Best Support QL?}

During the early years of the QL Design Team's existence, there were basically two organizations supporting QL efforts: the Mathematical Association of America (MAA) and the National Council on Education and the Disciplines, headed by Robert Orrill and funded by a Pew Foundation grant.

The MAA produced the Sons Report (Sons 1996) and in 2004 established a QL interest group that would organize sessions at national and regional meetings. Because courses that address QL concepts and skills were generally offered in mathematics departments, the support of the MAA was an enormous force for both promoting and improving QL offerings nationally. However, there were two major drawbacks to having the MAA as a potential parent organization for QL. First, because it represented all of undergraduate mathematics education, the MAA could devote only a small fraction of its resources and attention to promoting QL. Secondly, because MAA membership was composed almost exclusively of mathematicians and because the MAA held its meetings jointly with the American Mathematical Society, non-mathematicians were effectively discouraged from participation. The Design Team came to the conclusion that the support of the MAA, though appreciated, would not be enough to launch a real QL movement. Many subject areas would be strengthened by QL, and faculty in those areas had to be included.

The National Council on Education and the Disciplines (NCED), on the other hand, clearly recognized and valued the breadth of disciplines represented by the QL Design Team. However, NCED was not an academic association and did not possess the infrastructure to run one. Although it convened a major gathering at 
the National Academy of Sciences in 2001 (Madison and Steen 2003) with the support, in name only, of the MAA and the Mathematical Sciences Education Board of the NRC, this sort of effort was not sustainable. So the QL Design Team chose to create a network of QL centers that, at a meeting at Dartmouth in 2004, became the National Numeracy Network, a membership organization (Madison and Steen 2008). The NNN eventually incorporated as a nonprofit and currently stands as an autonomous organization promoting QL across the disciplines. The NNN has proven to be a voice at the national level, runs an annual meeting, and hosts Numeracy.

Despite its positive contributions, The NNN also has its disadvantages. For most of its members, the NNN is their second academic affiliation after their disciplinary organization. As initially conceived, it was a network of interested faculty and others - nothing more. It has certainly fulfilled that goal well. Because it seeks to represent faculty at two-year colleges as well as at less well funded four-year colleges, its dues are minimal. It has no paid staff. The projects the organization could undertake are limitless, but the attention and resources available for them are limited.

While the MAA has a considerable income stream from dues and grants, it has limited commitment to QL, as one interest among many, and it mostly serves mathematicians. The NNN is uniquely committed to promoting QL and serves a broader group, but it has essentially no income stream. Solving the second problem is more tractable than solving the first and doing so would create a much firmer foundation for the QL movement in general. External funding would allow the NNN to host a broader range of activities for its members. It would enable the NNN to apply for other sorts of grant support. And importantly, it would allow fuller participation of faculty from institutions with higher teaching loads by relieving some of the administrative and budgetary obligations of serving as an NNN officer or board member.

\section{Concluding Thoughts}

Questions are good and we need to keep asking them. The answers may change over time. The three questions that the QL Design Team could not answer easily still continue to guide the work of the NNN. I have tried to indicate what my own short answers would be. The question "What is numeracy?" needs to be interpreted on a population as well as an individual basis, so that institutions and perhaps whole countries can gauge their overall success at producing a citizenry richly diverse in quantitative skills. Issues of pedagogy are there to be addressed and, now that QL is more broadly desired and promoted, it will not be a distraction to do so. The NNN needs a firm financial footing to effectively serve the QL community and some effort and attention needs to go to this end. Those 
are my thoughts after remembering these questions. I'm sure others will have more to say.

\section{References}

Bossé, M. J. 1995. "The NCTM Standards in Light of the New Math Movement: A Warning!" The Journal of Mathematical Behavior. 14 (2): 171-201. https://doi.org/10.1016/0732-3123(95)90004-7.

Craig, Jeffrey, and Lynette Guzmán. 2018. "Six Propositions of a Social Theory of Numeracy: Interpreting an Influential Theory of Literacy." Numeracy 11 (2): Article 2. https://doi.org/10.5038/1936-4660.11.2.2.

Freeman, Scott, Sarah L. Eddy, Miles McDonough, Michelle K. Smith, Nnadozie Okoroafor, Hannah Jordt, and Mary Pat Wenderoth. 2014. "Active Learning Increases Student Performance in Science, Engineering, and Mathematics." Proceedings of the National Academy of Sciences 111 (23): 8410-8415. https://doi.org/10.1073/pnas.1319030111.

Frith, Vera, and Robert N. Prince. 2018. "The National Benchmark Quantitative Literacy Test for Applicants to South African Higher Education." Numeracy 11(2): Article 3. https://doi.org/10.5038/1936-4660.11.2.3.

Goffe, W. L., and D. Kauper. 2014. "A Survey of Principles Instructors: Why Lecture Prevails." The Journal of Economic Education 45 (4): 360-375. https://doi.org/10.1080/00220485.2014.946547.

Henderson, C., and M. H. Dancy. 2011. "Increasing the Impact and Diffusion of STEM Education Innovations," in "Invited paper for the National Academy of Engineering, Center for the Advancement of Engineering Education Forum, Impact and Diffusion of Transformative Engineering Education Innovations." https://www.nae.edu/File.aspx?id=36304

Klein, D. 2003. "A Brief History of American K-12 Mathematics Education in the 20th Century." In Mathematical Cognition, edited by James Royer, 175-259. Information Age Publishing.

Madison, Bernard L., and Lynn Arthur Steen, eds. 2003. Quantitative Literacy: Why Numbers Matter for Schools and College. Princeton NJ: National Council on Education and the Disciplines. https://www.maa.org/sites/default/files/pdf/QL/WhyNumeracyMatters.pdf

Madison, Bernard L., and Lynn Arthur Steen. 2008. "Evolution of Numeracy and the National Numeracy Network." Numeracy 1 (1): Article 2. https://doi.org/10.5038/1936-4660.1.1.2.

Sons, Linda, ed. 1996. Quantitative Reasoning for College Graduates: A Complement to the Standards. Washington, DC: Mathematical Association of America. http://www.maa.org/programs/faculty-anddepartments/curriculum-department-guidelines- 
recommendations/quantitative-literacy/quantitative-reasoning-collegegraduates.

Steen, Lynn Arthur. 2001. Mathematics and Democracy. The Case for Quantitative Literacy. Princeton, NJ: The National Council on Education and the Disciplines, xiii-xx. https://www.maa.org/sites/default/files/pdf/QL/MathAndDemocracy.pdf

Vacher, H. L. 2015. "Educational Assessment Is an Enduring Theme of Numeracy." Numeracy 8(1): Article 1. https://doi.org/10.5038/19364660.8.1.1.

Vigdor, J. L. 2012. "Solving America's Mathematics Education Problem." American Enterprise Institute for Public Policy Research. http://www.aei.org/publication/solving-americas-mathematicseducation-problem/

Waldrop, M. M. 2015. "The Science of Teaching Science." Nature 523 (7560): 272. https://doi.org/10.1038/523272a.

Wallace, Dorothy. 2009. "Parts of the Whole: Is Everything Equally Important?" Numeracy 2 (1): Article 7. https://doi.org/10.5038/1936-4660.2.1.7.

Wallace, Dorothy. 2013. "Parts of the Whole: When Variation is the Goal." Numeracy 6 (1): Article 8. https://doi.org/10.5038/1936-4660.6.1.8.

Wallace, Dorothy. 2017. "Parts of the Whole: Why I Teach This Subject This Way." Numeracy 10 (2): Article 17. https://doi.org/10.5038/19364660.10.2.17.

Wallace, Dorothy. 2018. "Parts of the Whole: Institutional Research, ServiceLearning, and NNN." Numeracy 11 (2): Article 15. https://doi.org/10.5038/1936-4660.11.2.15. 